\title{
Bepridil, a class IV antiarrhythmic agent, can block the TREK-1 potassium channel
}

\author{
Ying Wang ${ }^{1}$, Zhijie $\mathrm{Fu}^{1,2}$, Zhiyong $\mathrm{Ma}^{1}$, $\mathrm{Na} \mathrm{Li}^{1}$, Hong Shang ${ }^{3}$
}

${ }^{1}$ Key Laboratory of Cardiovascular Remodeling and Function Research, Chinese Ministry of Education and Chinese Ministry of Public Health, Department of Cardiology, Qilu Hospital, Shandong University, Jinan, China; ${ }^{2}$ Department of Otorhinolaryngology, the First Affiliated Hospital of Shandong First Medical University, Jinan, China; ${ }^{3}$ Key Laboratory of Cardiovascular Proteomics of Shandong Province, Department of Geriatrics, Qilu Hospital, Shandong University, Jinan, China

Contributions: (I) Conception and design: Y Wang, H Shang; (II) Administrative support: Z Ma, H Shang; (III) Provision of study materials or patients: Z Ma, Z Fu; (IV) Collection and assembly of data: Y Wang, N Li; (V) Data analysis and interpretation: Y Wang, Z Ma, Z Fu; (VI) Manuscript writing: All authors; (VII) Final approval of manuscript: All authors.

Correspondence to: Dr. Hong Shang, MD, PhD. West Wenhua Road 107, Qilu Hospital, Shandong University, Jinan 250014, China.

Email: 13573148930@139.com.

Background: The TWIK-related potassium channel (TREK-1) can be regulated by different stimuli. However, it is not clear whether some antiarrhythmics affect the activity of TREK-1. In the present study, the effect of bepridil on the TREK-1 currents is investigated.

Methods: In a TREK-1 stably-expressed HEK-293 cell line (HEK-TREK-1), U251MG cells, and isolated mouse ventricular myocytes, the TREK-1 current and action potentials were recorded by the patch-clamp technique. The standard voltage protocol was a $200 \mathrm{~ms}$ constant potential at $20 \mathrm{mV}$, followed bya $500 \mathrm{~ms}$ ramp from -90 to $+20 \mathrm{mV}$ (HEK-TREK-1) or $+80 \mathrm{mV}$ (U251MG cells and myocytes) every $10 \mathrm{~s}$. The currents at $+20 \mathrm{mV}$ or $+80 \mathrm{mV}$ were used for analysis. The docking study of bepridil's binding model in the TREK-1 channel was performed using the Swissdock web service.

Results: In HEK-TREK-1 cells, BL1249 induced a significantly large outwardly rectifying current with similar baseline TREK-1 current characteristic, with a reversal potential $(-70 \mathrm{mV})$. The concentration of half-maximal activation $\left(\mathrm{EC}_{50}\right.$ ) of BL1249 was $3.45 \mu \mathrm{M}$. However, bepridil decreased the baseline TREK1 currents, with a concentration of half-maximal inhibition $\left(\mathrm{IC}_{50}\right) 0.59 \mu \mathrm{M}$ and a Hill coefficient of 1.1. Also, bepridil inhibited BL1249-activated TREK-1 currents, with an $\mathrm{IC}_{50} 4.08 \mu \mathrm{M}$ and a Hill coefficient of 3.22. The outside-out patch-clamp confirmed bepridil inhibited BL1249-activated TREK-1 currents. In U251MG cells and myocytes, BL1249 activated outwardly rectifying endogenous TREK-1 currents, which could be inhibited by bepridil. BL1249 $(10 \mu \mathrm{M})$ could decrease the peak value and reduce the duration of the action potential. Bepridil $(10 \mu \mathrm{M})$ prolonged the duration of action potential of myocytes. The docking study revealed that bepridil might affect the $\mathrm{K}^{+}$pore domain and the $\mathrm{M} 4$ modulator pocket.

Conclusions: Bepridil may be a blocker for the TREK- $1 \mathrm{~K}^{+}$channel at a clinically therapeutic concentration, providing a new mechanism of TREK-1 regulation and bepridil's antiarrhythmic effect.

Keywords: TWIK-related potassium channel; antiarrhythmic drug; bepridil; patch clamp

Submitted Dec 15, 2020. Accepted for publication May 17, 2021.

doi: 10.21037/atm-20-7971

View this article at: https://dx.doi.org/10.21037/atm-20-7971

\section{Introduction}

The TWIK-related potassium channel (TREK-1) is an extensively studied member of the two-pore domain (K2P)
$\mathrm{K}^{+}$channel superfamily $(1,2)$. K2P channels share the same general structure, including four transmembrane helices (M1-M4) and two-pore domains (P1 and P2) $(3,4)$. The 
TREK-1 channel can be activated by different stimuli, such as membrane stretch, intracellular acidification (5), and polyunsaturated fatty acids (like arachidonic acid or volatile anesthetics) $(1,2)$. However, they are not blocked by conventional votage-gated $\mathrm{K}^{+}$channel inhibitors (4AP or TEA) and can be blocked by selective serotonin reuptake inhibitors (such as fluoxetine) (1), extracellular acidification (6), and some local anesthetics (7).

Recently, TREK-1 has been considered as a novel and major member of cardiac stretch-activated $\mathrm{K}^{+}$channel current $(8,9)$. The TREK-1-dependent pathway was found to be essential for normal sinoatrial node cell excitability (10). Lugenbiel et al. found that TREK-1 channels were suppressed in patients with atrial fibrillation and heart failure (11). As for the relationship between cardiovascular drugs andTREK-1 channels, a study reported that carvedilol concentration-dependently inhibited TREK-1 channels with frequency independence (12). However, a study regarding the regulation of anti-arrhythmia agent on the activity of TREK1 remains lacking.

Bepridil, a class IV antiarrhythmic agent, is a useful antiarrhythmic drug in the treatment of atrial fibrillation but exhibits adverse effects of proarrhythmia, such as torsades de pointes (TdP) and QT prolongation $(13,14)$. In addition to its nonselective calcium channel blockade, bepridil can inhibit several $\mathrm{K}^{+}$channels, including the rapidly- and slowly-activating delayed rectifier $\mathrm{K}^{+}$ channel currents $\left(\mathrm{I}_{\mathrm{Kr}}\right.$ with $\mathrm{IC}_{50}=13.2 \mu \mathrm{M}$ and $\mathrm{I}_{\mathrm{Ks}}$ with $\left.\mathrm{IC}_{50}=6.2 \mu \mathrm{M}\right)(15)$, BKca channels $\left(\mathrm{IC}_{50}=1.866 \mu \mathrm{M}\right)(16)$, $\mathrm{K}(\mathrm{ATP})$ channels $\left(\mathrm{IC}_{50}=6.6 \mu \mathrm{M}\right)(17)$, among others. The concentration relevant to the therapeutic plasma concentrations in clinical use was $2-3 \mu M(18)$. Since $\mathrm{Ca}^{2+}$ store-active drugs were reported to block TREK1 channels $(18,19)$, it is intriguing to investigate whether bepridil can regulate the TREK-1 activity at a clinically therapeutic concentration.

Furthermore, BL1249 has previously been validated to be specifically active in the TREK-1 channel, not only in heterologous expression systems but also in primary cells $(20,21)$, which act on a gating mechanism involving a site located below the selectivity filter and the C-type gate (2). However, there is no study investigating whether bepridil can affect BL1249-activated TREK-1 current. In the present study, we evaluated the effect of bepridil on exogenous and endogenous basal and BL1249-activated TREK-1 channels using patch-clamp techniques. We present the following article in accordance with the ARRIVE reporting checklist (available at https://dx.doi. org/10.21037/atm-20-7971).

\section{Methods}

\section{Cell culture}

A TREK-1 stably-expressed HEK-293 cell line (described previously) was used (22). U251MG human glioblastoma cells were obtained from ATCC (USA). Both cells were maintained in Dulbecco's modified Eagle's medium (DMEM) at $37{ }^{\circ} \mathrm{C}$ in a $5 \% \mathrm{CO}_{2}$ incubator. Fetal bovine serum $(10 \% \mathrm{~V} / \mathrm{V})$, streptomycin $(0.1 \mathrm{mg} / \mathrm{mL})$, and penicillin $(100 \mathrm{U} / \mathrm{mL})$ were added into the DMEM.0.1\% of Geneticin G-418 sulfate (purchased from Invitrogen, USA) was used to maintain the selected TREK-1 stablyexpressed cells.

\section{Isolation of cardiac myocytes}

The cardiac myocytes were separated from the left ventricle of mice using the method reported by our previous study (23). Male Kunming mice at eight weeks old (20-40 g) were anesthetized with intraperitoneal injection of pentobarbitone sodium at a concentration of $30-40 \mathrm{mg} / \mathrm{kg}$ and heparin $(100 \mathrm{U} / \mathrm{kg})$. Next, the mice hearts were perfused with calcium-free Joklik MEM (Sigma) solution for $5 \mathrm{~min}$, followed by collagenase digestion solution $(1 \mathrm{mg} / \mathrm{mL}$ collagenase $\Pi$ and $1 \mathrm{mg} / \mathrm{mL}$ bovine serum albumin) for about 15 minutes using a Langendorff apparatus at $37^{\circ} \mathrm{C}$. The left ventricles were sheared to $1 \mathrm{~mm}^{3}$ pieces and gently triturated to isolate the myocytes in $\mathrm{KB}$ solution $(30 \mathrm{mM}$

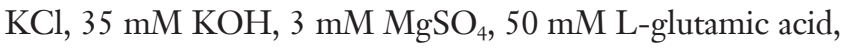
$0.5 \mathrm{mM}$ EGTA, $20 \mathrm{mM}$ taurine, $10 \mathrm{mM}$ glucose, and $10 \mathrm{mM}$ HEPES; adjustpH to 7.2 using $\mathrm{KOH}$ solution). More than three myocytes from three different mice were used for the following experiments.

Ethical statement: experiments were performed under a project license (No.: DWLL-2020-042) granted by the Animal Care Committee of Qilu Hospital of Shandong University, in compliance with the Guide for the Care and Use of Laboratory Animals published by the United States National Institutes of Health.

\section{Whole-cell patch-clamp recordings}

The whole-cell patch-clamp technique was described in our previously published papers (23). Trypsin was used to detach the cultured cells, which were planted onto glass coverslips 
at least $30 \mathrm{~min}$ prior to patch clamp recordings and continuously perfused with the standard bath solution (SBS). Whole-cell $\mathrm{K}^{+}$currents were recorded at room temperature with a standard ramp-step protocol: a $200 \mathrm{~ms}$ step pulse to $20 \mathrm{mV}$, followed by a $500 \mathrm{~ms}$ ramp from -90 to $+20 \mathrm{mV}$ (HEK-293 cell) or $+80 \mathrm{mV}$ (U251MG cell and cardiac myocytes) every $10 \mathrm{~s}$, from a holding potential of $-90 \mathrm{mV}$. Electrical signal was amplified by a patch-clamp amplifier (EPC-10, HEKA, Lambrecht, Germany) and manipulated by Pulse software (HEKA, Lambrecht, Germany). The currents at $+20 \mathrm{mV}$ or $+80 \mathrm{mV}$ were recorded to analyze the differences between different treatments, and the currents of ramp pulse were used for I-V relationship analysis.

For dose-dependent analysis, the cells were perfused with SBS and a series of different concentrations of BL1249 or bepridil $(0.1,0.3,1,3$, and $10 \mu \mathrm{M})$. The concentrations were determined according to previous studies; the highest concentration of bepridil was usually $10 \mu \mathrm{M}$ and $\mathrm{IC}_{50}$ toI $\mathrm{I}_{\mathrm{Ks}}$ $=6.2 \mu \mathrm{M}(15), \mathrm{IC}_{50}$ to BKca channels $=1.866 \mu \mathrm{M}$ (16), and $\mathrm{IC}_{50}$ to $\mathrm{K}(\mathrm{ATP})$ channels $=6.6 \mu \mathrm{M}(17)$. The mean current of more than three cells from three different experiments was recognized as the final channel current of each experiment. The Origin and IGOR software were used to analyze all recordings. To normalize the membrane currents to cell size, the currents were divided by the capacitances of cell membrane to obtain the current density $(\mathrm{pA} / \mathrm{pF})$.

\section{Excised outside-out patch-clamp}

Excised outside-out patch-clamp configurations were made according to previous studies $(24,25)$. In the outsideout patch-clamp, the pipette solution was identical to the whole-cell patch, and the perfusion solution was SBS. The recording protocol was also the same as the standard rampstep protocol used in the whole-cell patch.

\section{Action potential recording}

In the whole-cell and current-clamp modes, the action potential was induced by 1.5 times the threshold depolarization current (800-1,000 pA, duration $10 \mathrm{~ms})$.

\section{Docking model of bepridil binding in the TREK-1 channel}

A target protein structure of TREK-1 (PDB\# 6CQ6) was selected in the Protein Data Bank (PDB, http://www.pdb. org) (26). The structure of bepridil (ZINC3812918) was obtained from the ZINC database (27). Docking steps were performed using the SwissDock molecular docking web service (http://www.swissdock.ch/docking) (28). The results were downloaded and visualized in the UCSF Chimera program (29).

\section{Reagents and solutions}

SBS was constituted as follows: $\mathrm{NaCl}(140 \mathrm{mM}), \mathrm{KCl}$ (5 mM), $\mathrm{MgCl}_{2}(1 \mathrm{mM}), \mathrm{CaCl}_{2}(2 \mathrm{mM})$, HEPES $(10 \mathrm{mM})$, and glucose $(10 \mathrm{mM})$. The $\mathrm{pH}$ of SBS was adjusted to 7.4 by adding $\mathrm{NaOH}(2 \mathrm{mM})$ and the osmolarity was adjusted to $290 \mathrm{mOsm}$ using D-Mannitol. The pipette solution was constituted as follows: $10 \mathrm{mM} \mathrm{NaCl}, 117 \mathrm{mM} \mathrm{KCl}, 2 \mathrm{mM}$ $\mathrm{MgCl}_{2}, 10 \mathrm{mM}$ HEPES, and $10 \mathrm{mM}$ EGTA (adjust $\mathrm{pH}$ to 7.2 by adding $2 \mathrm{mM} \mathrm{KOH}$ ); and $5 \mathrm{mM} \mathrm{Na} \mathrm{ATP}_{2} \mathrm{AT}$ was added during AP recording. BL1249 and bepridil were dissolved in dimethylsulfoxide (DMSO) and diluted in SBS immediately before each experiment. All reagents were purchased from Sigma Aldrich.

\section{Data and statistical analysis}

Statistical analysis was performed using SPSS 23.0 software according to our previous studies. Means \pm standard deviation was used to present the data. One-way ANOVA with a post-hoc comparison was used for comparing differences among the different treatments. Sigmaplot software was used to calculate the $\mathrm{EC}_{50}$ (the concentration of half-maximal activation) or the $\mathrm{IC}_{50}$ (the concentration of half-maximal inhibition). The fitting curves for concentration-response was from this equation: $I=a /[1$ $\left.+\left(\mathrm{EC}_{50} / \text { concentration }\right)^{\mathrm{nH}}\right]$, 'a' was the current at $+20 \mathrm{mV}$ and $\mathrm{nH}$ was the Hill coefficient. The fitting curves for concentration-inhibition was from this equation: $f=a /[1+$ $\left.\left(\mathrm{IC}_{50} / \mathrm{D}\right)^{\mathrm{nH}}\right]$, where ' $\mathrm{a}$ ' was the current at $+20 \mathrm{mV}$ and $\mathrm{D}$ was the fractional block obtained at various drug concentrations. Statistical significance was regarded as $\mathrm{P}<0.05$.

\section{Results}

\section{Verification of TREK-1 currents in stably-expressed HEK-293 cells}

We observed that inTREK-1 stably-expressed HEK293 cells, the whole-cell patch-clamp recorded the baseline outward rectified currents. The I-V relationship revealed the reversal potential of the currents was $-70 \mathrm{mV}$, approaching the $\mathrm{K}^{+}$equilibrium potential (Figure 1A,B). 
A

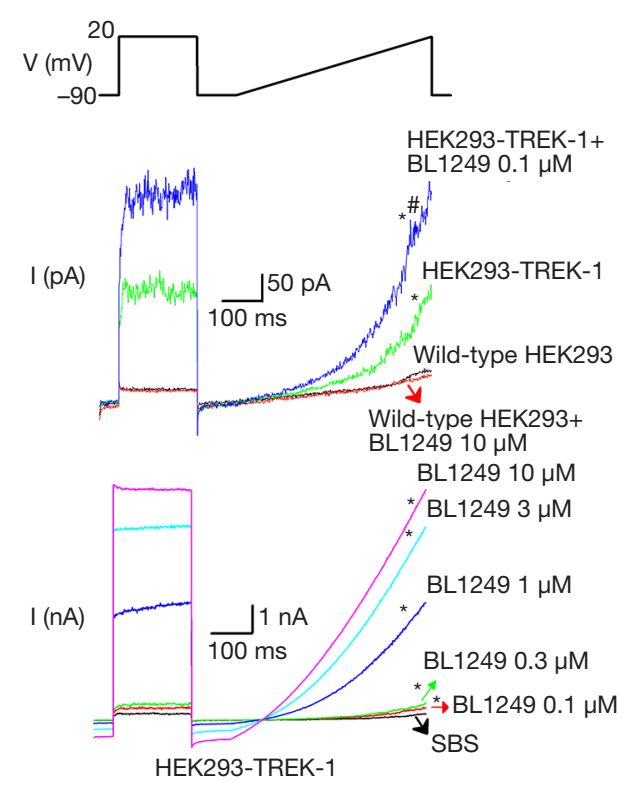

B
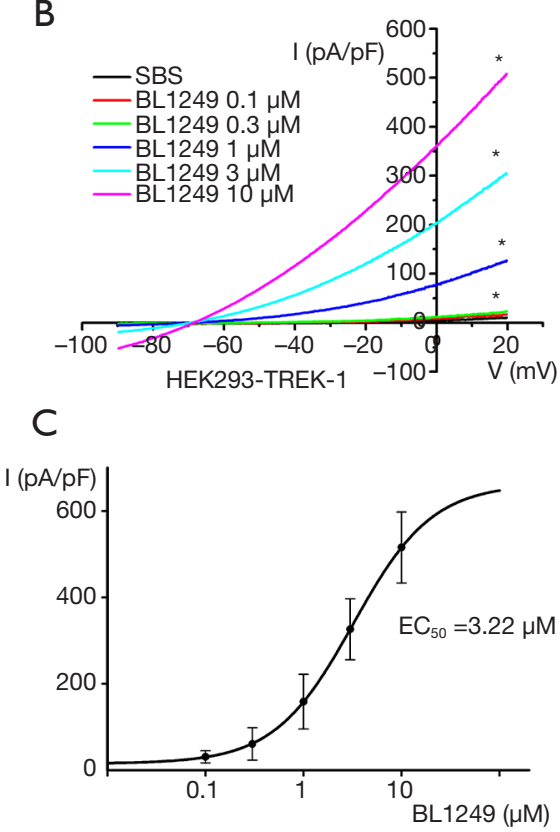

Figure 1 TREK-1 currents in stably-expressed HEK-293 cells (n=3-5). (A) A standard ramp-step protocol and representative traces of baseline and BL1249-activated TREK-1 currents: a $200 \mathrm{~ms}$ step pulse to $20 \mathrm{mV}$, subsequent a $500 \mathrm{~ms}$ ramp from -90 to $+20 \mathrm{mV}$ with an interval of $10 \mathrm{~s}$ and a holding potential of $-90 \mathrm{mV}$. (B) The relevant current-voltage (I-V) relationship at the last sweeps of different treatments recorded with the standard ramp-step protocol; the currents displayed significantly outward rectified characteristic, the reversal potential was $-70 \mathrm{mV}$, approaching the potassium equilibrium potential. (C) Concentration-dependent fitting curves of BL1249 activation, $\mathrm{EC}_{50}=3.22 \mu \mathrm{M} .{ }^{*} \mathrm{P}<0.05$, comparing data at different treatments with that of TREK-1 stably-expressed HEK-293 cells in SBS; ${ }^{\#} \mathrm{P}<0.05$, comparing data at different treatments with that of wild-type HEK-293 cells in SBS.

We also found BL1249, a putative activator of the TREK1 channel (30), activated a significantly large outwardly rectifying current with similar characteristics of baseline current (Figure $1 A, B$ ). The $\mathrm{EC}_{50}$ of BL1249 was $3.22 \mu \mathrm{M}$ (Figure 1C). However, conventional votage-gated $\mathrm{K}^{+}$channel inhibitors 4-AP and TEA could not affect the currents (data not shown). The basal current was $10.33 \pm 3.53 \mathrm{pA} / \mathrm{pF}$, and the currents $(\mathrm{pA} / \mathrm{pF})$ at $0.1,0.3,1,3$, and $10 \mu \mathrm{M}$ BL1249 were $17.25 \pm 10.13,23.57 \pm 15.39,126.81 \pm 134.10$, $304.24 \pm 163.98$, and $508.49 \pm 200.94$, respectively.

\section{Effect of bepridil on the TREK-1 activity in TREK-1 stably-expressed HEK-293 cells}

We found that bepridil $(10 \mu \mathrm{M})$ could quickly decrease the baseline TREK-1 currents (Figure 2A,B). Concentrationdependence analysis demonstrated that the $\mathrm{IC}_{50}$ of bepridil's blockade to baseline TREK-1 was $0.59 \mu \mathrm{M}$ and the Hill coefficient $(\mathrm{nH})$ was 1.1 (Figure $2 C, D$ ). The basal current was $51.28 \pm 45.66 \mathrm{pA} / \mathrm{pF}$, and the currents $(\mathrm{pA} / \mathrm{pF})$ at $0.1,0.3,1,3$, and $10 \mu \mathrm{M}$ bepridil were $47.54 \pm 49.83$, $34.39 \pm 33.33,17.85 \pm 11.56,8.93 \pm 0.45$, and $1.03 \pm 0.21$, respectively.

Bepridil $(10 \mu \mathrm{M})$ also decreased BL1249 (10 $\mu \mathrm{M})$ activated TREK-1 currents (Figure $3 A, B$ ). Concentrationdependence analysis demonstrated the $\mathrm{IC}_{50}$ of bepridil's blockade to BL1249-activated TREK-1 was $4.078 \mu \mathrm{M}$ and the Hill coefficient $(\mathrm{nH})$ was 3.2 (Figure 3 C).

However, bepridil $(10 \mu \mathrm{M})$ only partly inhibited BL1249 $(10 \mu M)$-activated TREK-1 compared with the baseline TREK-1 currents (Figure 2B, Figure 3B). The $\mathrm{IC}_{50}$ of bepridil on the basal current $(0.59 \mu \mathrm{M}$ with a Hill coefficient of 1.1) was markedly different from the $\mathrm{IC}_{50}$ of bepridil on the BL1249-induced current. When treated with higher concentrations of bepridil, the HEK-293 cells were not tolerant to the stimulation.

In addition, the outside-out patch-clamp configuration confirmed that bepridil could inhibit BL1249-induced TREK-1 currents (Figure 3D). The negative control reagent, DMSO, did not affect all experiments. 
A

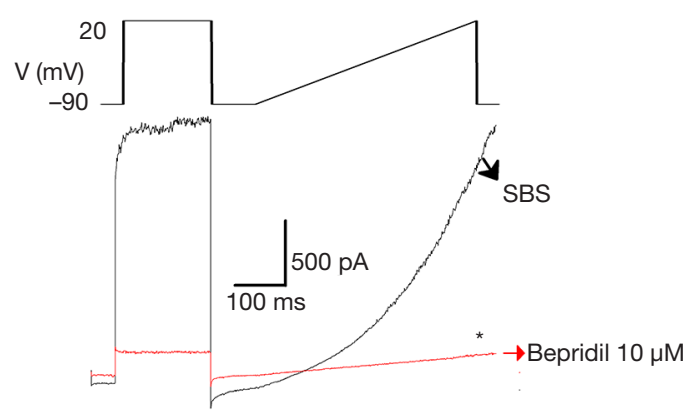

B

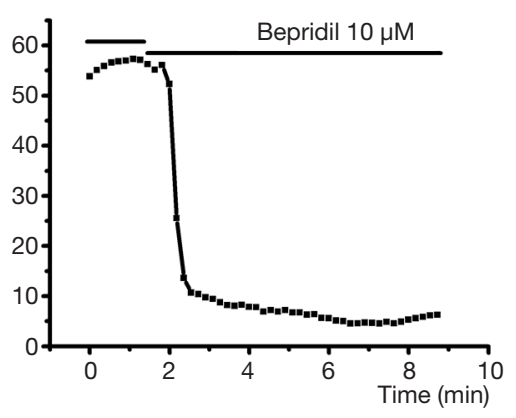

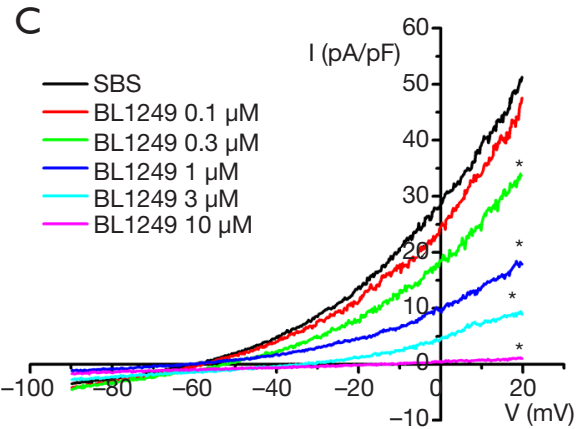

D

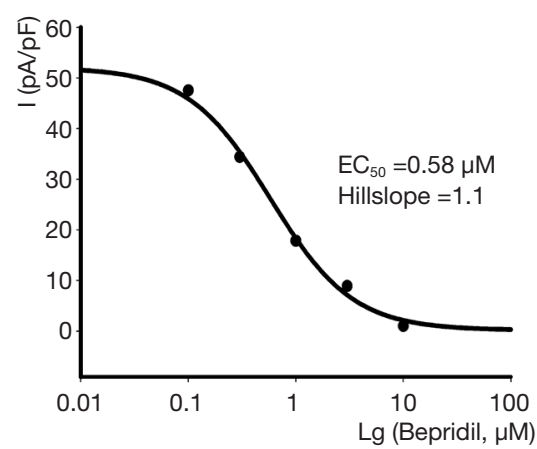

Figure 2 Effect of bepridil on the baseline TREK-1 activityin the whole-cell patch-clamp (n=3-5). (A) A standard ramp-step protocol and representative traces of baseline- and bepridil-regulated TREK-1 currents: a $200 \mathrm{~ms}$ step pulse to $20 \mathrm{mV}$, subsequent a $500 \mathrm{~ms}$ ramp from -90 to $+20 \mathrm{mV}$ with an interval of $10 \mathrm{~s}$ and a holding potential of $-90 \mathrm{mV}$. (B) Time series analysis of bepridil (10 $\mu \mathrm{M})$ on the basal TREK1 currents. (C) The relevant current-voltage (I-V) relationship at the last sweep of different bepridil concentrations using the standard ramp-step protocol. (C) Concentration-dependent fitting curves of bepridil inhibition, $\mathrm{IC}_{50}=0.59 \mu \mathrm{M}$, and Hill coefficient $=1.1$. ${ }^{*} \mathrm{P}<0.05$, comparing data at different treatments with that in SBS.

\section{Effect of bepridil on the TREK-1 activityin U251MG cells}

In another experiment, we detected TREK-1 expression in U251MG cells (Supplemental data). We found that BL1249 $(30 \mu \mathrm{M})$ activated a considerably large outwardly rectifying TREK-1 current (Figure $4 A, B$ ). At times, BL1249 $(10 \mu \mathrm{M})$ was insufficient to induce TREK1 current (data not shown). Bepridil $(10 \mu M)$ decreased BL1249 $(30 \mu \mathrm{M})$-activated TREK-1 currents (Figure 4C). The basal current was $335.89 \pm 141.27 \mathrm{pA} / \mathrm{pF}$, and the BL1249 $(30 \mu \mathrm{M})$-induced current was $1,543.14 \pm 124.88$ $\mathrm{pA} / \mathrm{pF}$, which was decreased to $921.95 \pm 841.79 \mathrm{pA} / \mathrm{pF}$ by bepridil (Figure $4 D, \mathrm{P}<0.05$ ).

\section{Effect of bepridil on TREK-1 activity in cardiac myocytes}

In mouse ventricular myocytes, BL1249 $(10 \mu \mathrm{M})$ activated a significantly large outwardly rectifying TREK-1current.
The I-V relationship revealed the reversal potential of the current was $-80 \mathrm{mV}$, approaching the $\mathrm{K}^{+}$equilibrium potential of cardiacmyocytes, which could be inhibited by bepridil $(10 \mu \mathrm{M}$, Figure $5 A, B)$.

We observed that BL1249 $(10 \mu \mathrm{M})$ could decrease the peak value $(-5.02 \pm 50.72 \mathrm{mV}, \mathrm{P}<0.05)$ and reduce the duration of action potential $(182.2 \pm 114.81 \mathrm{~ms}$, $\mathrm{P}<0.05)$, compared with the control $(33.58 \pm 45.54 \mathrm{mV}$ and $356.65 \pm 65.56 \mathrm{~ms}$, respectively). Compared with the control and BL1249, bepridil $(10 \mu M)$ increased the peak value of action potential $(63.34 \pm 12.46 \mathrm{mV}, \mathrm{P}<0.05)$ and prolonged the duration of action potential $(477 \pm 46.67 \mathrm{~ms}$, $\mathrm{P}<0.05$, Figure 5C). When treated with both BL1249 and bepridil, the myocytes were not tolerant to the current stimulation. The resting membrane potential did not vary among the different treatment: SBS $(-86.78 \pm 4.31 \mathrm{mV})$, BL1249 $(10 \mu \mathrm{M},-87.36 \pm 6.70 \mathrm{mV})$, and BL1249 $(10 \mu \mathrm{M}$, $-85.25 \pm 2.39 \mathrm{mV}$ ). 
A

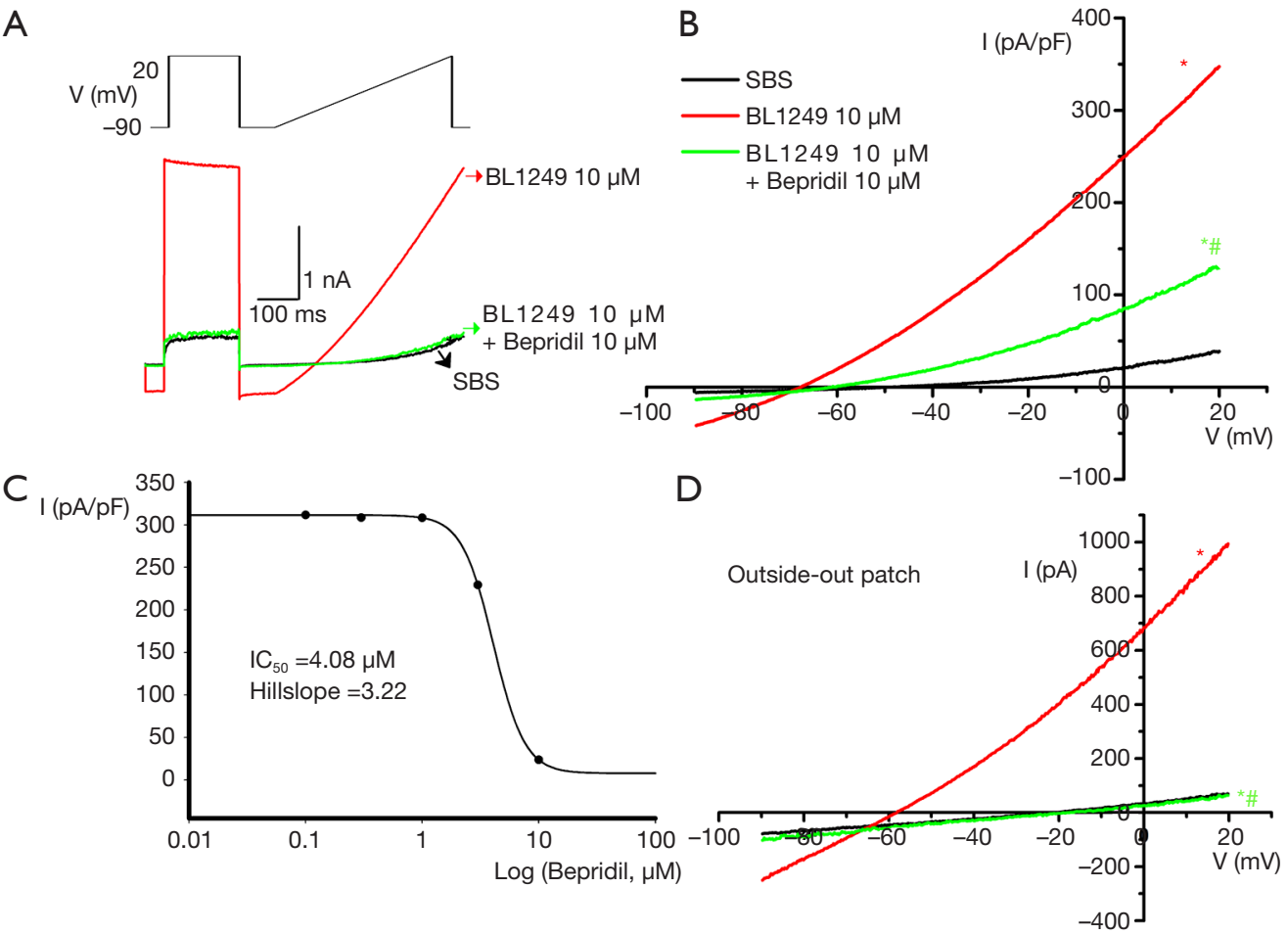

Figure 3 Effect of bepridil on BL1249 induced TREK-1activity (n=3-5). (A) A standard ramp-step protocol and representative traces of BL1249 $(10 \mu \mathrm{M})$ - and bepridil $(10 \mu \mathrm{M})$-regulated TREK-1 currents: a $200 \mathrm{~ms}$ step pulse to $20 \mathrm{mV}$, subsequent a $500 \mathrm{~ms}$ ramp from -90 to $+20 \mathrm{mV}$ with an interval of $10 \mathrm{~s}$ and a holding potential of $-90 \mathrm{mV}$. (B) The whole-cell patch-clamp, relevant current-voltage (I-V) relationship at the last sweep of BL1249 $(10 \mu \mathrm{M})$ and bepridil $(10 \mu \mathrm{M})$ obtained with the standard ramp-step protocol. (C) Concentrationdependent fitting curves of bepridil inhibition of the BL1249-activated TREK-1 current at $+20 \mathrm{mV}, \mathrm{IC}_{50}=4.078 \mu \mathrm{M}$, Hill coefficient $=3.22$. (D) The outside-out patch-clamp, current-voltage (I-V) relationships at the last sweep of BL1249 (10 $\mu \mathrm{M})$ and bepridil (10 $\mu \mathrm{M})$ obtained with the standard ramp-step protocol. ${ }^{*} \mathrm{P}<0.05$, comparing data at different treatments with that in $\mathrm{SBS}$; ${ }^{\#} \mathrm{P}<0.05$, compared data at different treatments with that inBL1249.

\section{Docking model of bepridil binding in theTREK-1 channel}

Docking into 6CQ6 TREK-1 K2P2.1 (TREK-1) apo structure showed that bepridil was near the $\mathrm{K}^{+} \mathrm{P} 1$ and $\mathrm{P} 2$ pore helix and the M4 modulator pocket (Figure 6).

\section{Discussion}

Increasing evidence has demonstrated that TREK-1 channels play a key role in human cardiac arrhythmias' pathogenesis (8-10). Bepridil has been used as an antiarrhythmic drug with multiple effects on several ion channels (31-33). For the first time, our study revealed bepridil was able to inhibit TREK-1 currents in a concentration-dependent manner.

TREK-1 channels were initially found in the nervous system and play a key role in neuronal excitability, pain conduction, neuroprotection, and depression $(34,35)$. Subsequently, TREK-1 channels were detected in intestinal smooth muscle (19), urinary bladder (30), heart (8), nasal epithelia (36), etc. Particularly, in the cardiovascular system, TREK-1 channels were expressed in atrial myocytes $(10,11)$, ventricular myocytes (24), and mesenteric arteries (37). Since TREK-1 is a good candidate for background potassium currents and membrane potential in these cell types, it is clear that TREK-1 channels may have a critical role in regulating cardiac action potential duration and mediating the vasodilator response of resistance arteries to their stimuli of stretch, polyunsaturated fatty acids, intracellular and extracellular $\mathrm{pH}$, and neurotransmitters (8-11). Therefore, TREK-1 may be a major therapeutic target to treat cardiovascular diseases.

However, the regulatory mechanism for TREK-1 
A

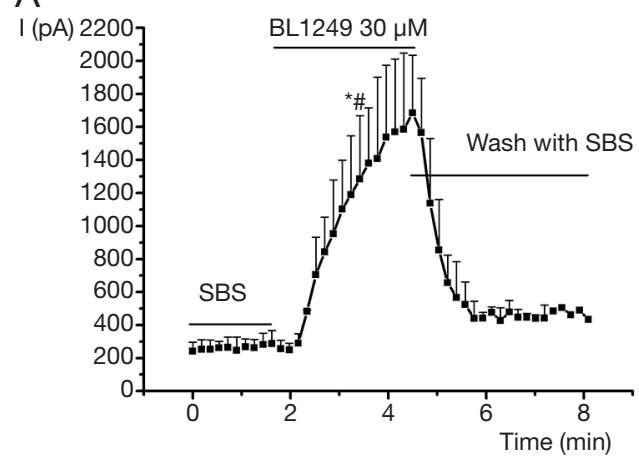

C

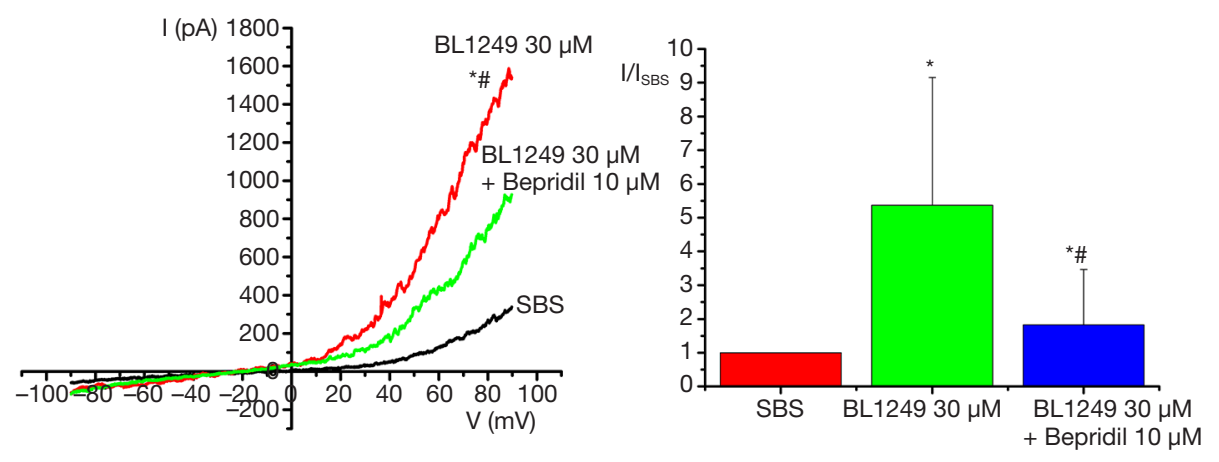

B

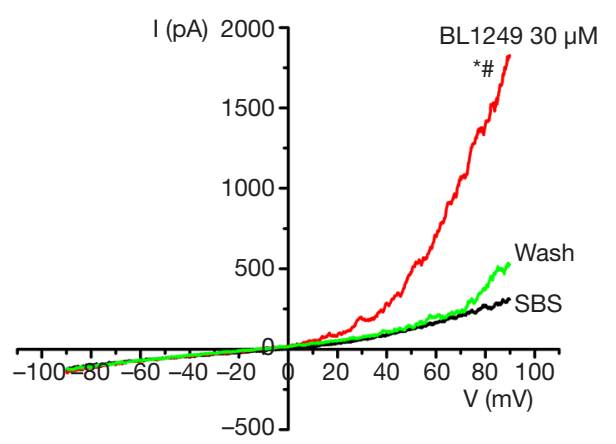

D

Figure 4 Effect of bepridil on TREK-1 activityin U251MG cells (n=3-5). A, Time-series changes of currents at $+80 \mathrm{mV}$. (B,C) The relevant current-voltage (I-V) relationship at the end of BL1249 $(30 \mu \mathrm{M})$ and bepridil $(10 \mu \mathrm{M})$ treatment obtained with the standard ramp-step protocol. BL1249 $(30 \mu \mathrm{M})$ activated a very large outwardly rectifying TREK-1 current. (D) Statistical results of currents at $+80 \mathrm{mV}$; bepridil $(30 \mu \mathrm{M})$ decreased BL1249 $(10 \mu \mathrm{M})$-activated TREK-1 currents. The raw data was normalized current by calculating the ratio between the current with different drugs and the same cell's basal current. ${ }^{*} \mathrm{P}<0.05$, comparing data at different treatments with that in SBS; ${ }^{*} \mathrm{P}<0.05$, compared data at different treatments with that in BL1249.

channel activity is not entirely clear. Several studies have investigated how cardiovascular drugs affected the activity of the TREK-1 channel. Bond et al. found that noradrenaline inhibited the TREK potassium channel currents through $\beta 1$ - and $\beta 2$-adreno receptor in the myocytes from rat atrium (38). As a $\beta$-receptor antagonist, carvedilol concentration-dependently inhibited TREK1 and TREK-2 channels, a process that was modulated by alternative mRNA translation initiation (12). In a study about the effect of antiarrhythmic drugs on K2P channels, vernakalant was found to inhibit K2P2.1 (TREK-1) but did not significantly reduce K2P3.1 currents (39).

In the present study, the whole-cell patch clamp revealed that bepridil could inhibit both baseline and BL1249activated TREK-1 currents in TREK-1 stably-expressed HEK-293 cells. The bepridil inhibition was concentrationdependent, with an $\mathrm{IC}_{50} 0.59 \mu \mathrm{M}$ (baseline) and $4.08 \mu \mathrm{M}$
(BL1249 activated). Compared with the baseline inhibition, bepridil at $10 \mu \mathrm{M}$ only partly blocked the BL1249-activated TREK-1 current. This different inhibition effect might result from the reverse use dependence of bepridil, which is a characteristic of most potassium channel blockers (as class III antiarrhythmic drugs) (40). In addition, Wang et al. found that bepridil might inhibit $\mathrm{I}_{\mathrm{Ks}}$ by interacting with the channel molecule one for one, with an $\mathrm{IC}_{50} 6.2 \mu \mathrm{M}$ (15). High concentrations $(>10 \mu \mathrm{M})$ of bepridil were found to depress $\mathrm{I}_{\mathrm{Kr}}$, with an $\mathrm{IC}_{50} 13.2 \mu \mathrm{M}$ and Hill coefficient 3.03, suggesting the inhibition might resulted from a cooperative way between the two molecules. In our study, the Hill coefficient for bepridil inhibition of basal TREK-1 current was 1.1, and 3.22 for bepridil inhibition of BL1249activated TREK-1 current. Furthermore, the outside patch-clamp confirmed that bepridil could inhibit TREK-1 currents. These results suggested that bepridil might block 
A
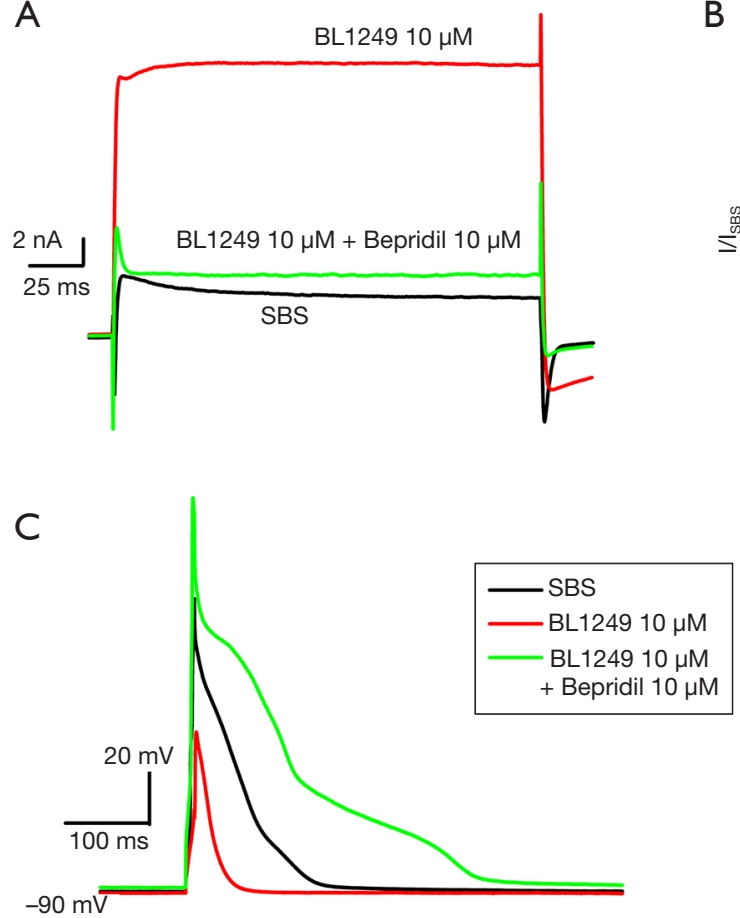

B

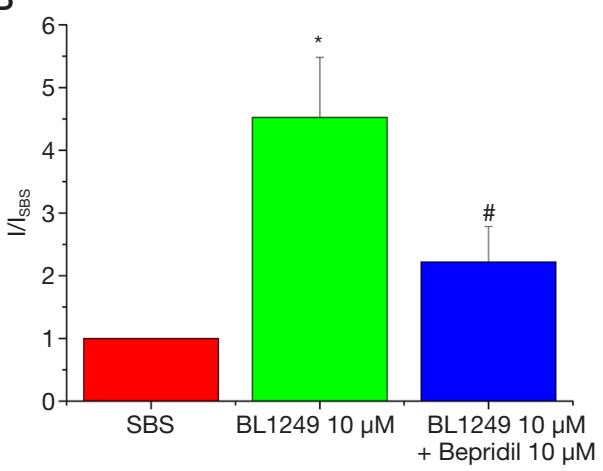

Figure 5 Effect of bepridil on TREK-1 activityin mouse ventricular myocytes (n=3-5). (A) representative traces of BL1249 (10 $\mu M$ )- and bepridil $(10 \mu \mathrm{M})$-regulated TREK-1 currents, with a $200 \mathrm{~ms}$ step pulse to $80 \mathrm{mV}$, from a holding potential of $-90 \mathrm{mV}$. B, Statistical analysis showed that BL1249 $(10 \mu \mathrm{M})$ activated a very large outwardly rectifying TREK-1 current; there versal potential was $-80 \mathrm{mV}$, approaching the $\mathrm{K}^{+}$equilibrium potential; the current could be inhibited by bepridil $(10 \mu \mathrm{M})$. (C) Action potential recording showed that BL1249 $(10 \mu \mathrm{M})$ could decrease the peak value and reduce the duration of action potential; bepridil $(10 \mu \mathrm{M})$ prolonged the action potential duration. The raw data was normalized current by calculating the ratio between the current with different drugs and the same cell's basal current. ${ }^{*} \mathrm{P}<0.05$, comparing data at different treatments with that in SBS; ${ }^{*} \mathrm{P}<0.05$, compared data at different treatments with that in BL1249.

the TREK-1 channel directly at a clinically therapeutic concentration.

To confirm these results, we investigated the effect of bepridil on the endogenous TREK-1 channel. In U251MG cells, BL1249 also activated an outwardly rectifying TREK1 current, which could be inhibited by bepridil. In mouse ventricular myocytes, BL1249 activated a significantly large outwardly rectifying TREK-1 current, which could be inhibited by bepridil $(10 \mu \mathrm{M})$. Our results demonstrated that bepridil might be a blocker of the TREK-1 channel.

Moreover, we evaluated the role of TREK-1 in the electrophysiology of cardiacmyocytes. BL1249 $(10 \mu M)$ could decrease the peak value and reduce the duration of the action potential. A similar finding was also demonstrated in previous studies. TREK-1 KO cardiacmyocytes reportedly exhibited action potential duration (APD) prolongation (41). Sinoatrial node cells displayed defects in cell electrophysiology and a loss of normal TREK-1 membrane localization in cardiac- specific TREK-1 deficient mice (10). These results suggested that TREK-1 could regulate the resting membrane potential and excitability of cardiacmyocytes.

Due to intolerance of the current stimulation with both BL1249 and bepridil, we could not explore the direct effect of bepridil on TREK-1-induced action potential changes. A possible reason might be that bepridil induced selective apoptosis, even in the presence of the protective stroma (42). However, bepridil alone prolonged the duration of action potential. Bepridil has been found to prolong the action potential duration of the ventriculus from guinea pigs, dogs, or rabbits (43). In patients with paroxysmal AF, bepridil $(172 \pm 26 \mathrm{mg} /$ day $)$ markedly prolonged the monophasic action potential durations and QT intervals (13). A possible mechanism for this phenomenon was that bepridil might act as a multi- $\mathrm{K}^{+}$channel blocker. Bepridil was initially developed as a calcium channel blocker used to treat angina. It subsequently was found to inhibit several potassium 

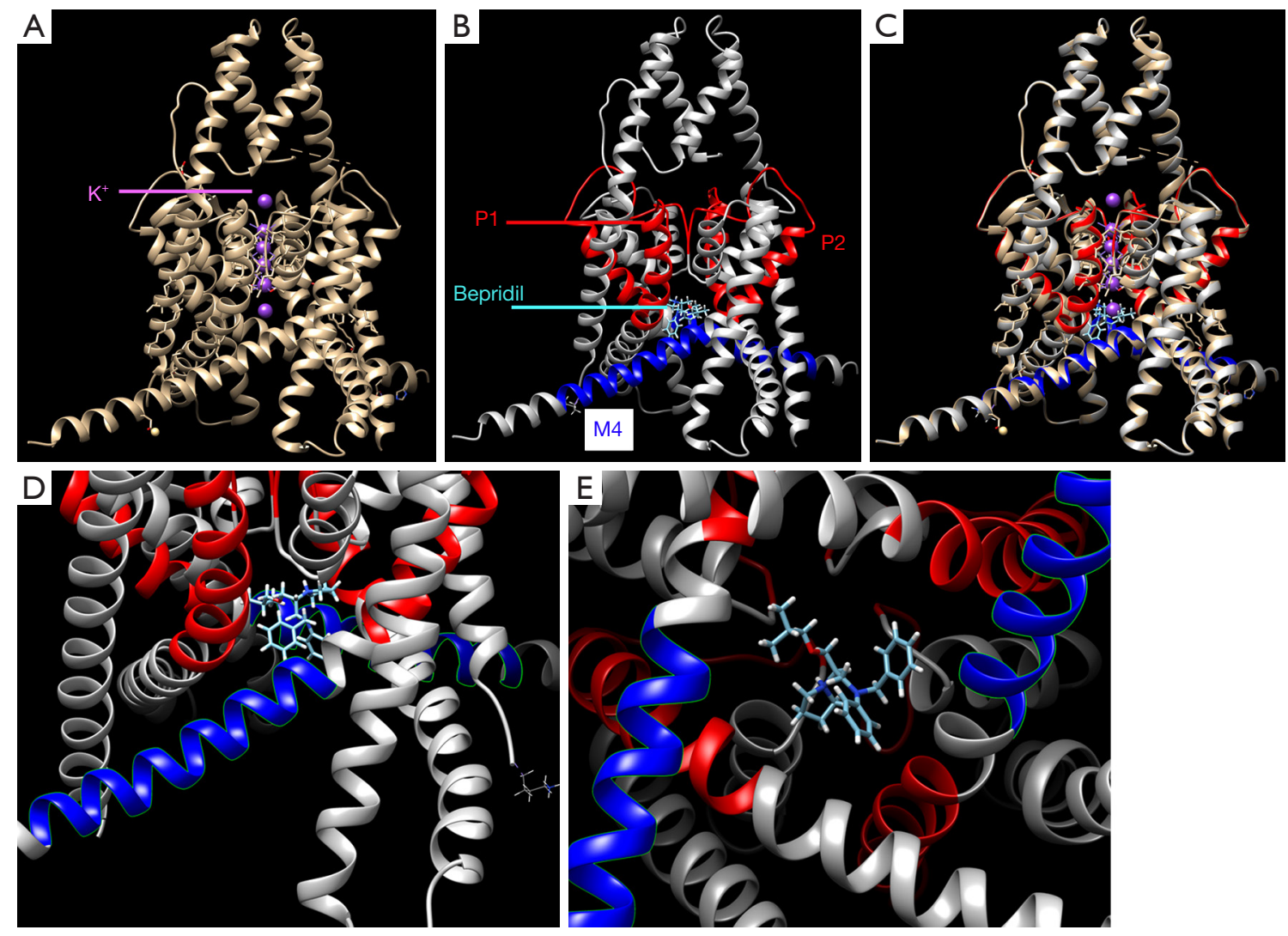

Figure 6 Predicted antagonist binding mode concerning the known TREK-1 modulator site. (A) 6CQ6 K2P2.1 (TREK-1) apo structure shows the $\mathrm{K}^{+}$(highlighted in purple) pore helix; (B) docking of bepridil (highlighted in light blue) into the 6CQ6 TREK-1 channel; bepridil is near the P1 and P2 pore helix and the M4 modulator pocket; $(\mathrm{C})$ merged docking structure; bepridil is proximal to the $\mathrm{K}^{+}$pore; (D,E) enlarged view of the antagonist binding region, which confirms that bepridil is in the $\mathrm{K}^{+}$pore and the M4 modulator pocket.

channels, including stretch-activated BKca channels (16) and inward-rectifier potassium current (44). When bepridil was added in the culture medium for $24 \mathrm{~h}$, it could reduce $\mathrm{I}_{\mathrm{K} 1}$ inneonatal cardiacmyocytes with $\mathrm{IC}_{50}=2.7 \mu \mathrm{M}$ (44). When being docked into 6CQ6 TREK-1 K2P2.1 apo structure, bepridil was space-filling to the $\mathrm{P} 1$ and $\mathrm{P} 2$ pore domain, and the M4 modulator pocket, which had been verified to be the key modulator of TREK-1 (45). Therefore, our results, coupled with those of previous studies, provide a new mechanism of bepridil's multiple nonselective effects on several ion channels and proarrhythmia.

Also, TREK-1 was studied to have a vital role in several cardiovascular diseases. Atrial KCNK2 (TREK-1) mRNA and protein expression were significantly reduced in patients with impaired left ventricular function (46). In atrial fibrillation subjects, down-regulation of atrial and ventricular KCNK2 mRNA and protein levels was observed.
TREK-1 gene was heterozygously mutated in a patient with idiopathic right ventricular outflow tract tachycardia (47). Moreover, the up-regulation of TREK-1 mRNA expression has been detected in rat ventriculus suffered from TACinduced pressure overload (8). These findings, coupled with our results, reveal the effect of TREK-1 on regulating the action potential of cardiacmyocytes and the blockade of bepridil to TREK-1 at a clinically therapeutic concentration, which provides important evidence that identifies the role of TREK-1 in cardiovascular diseases and therapy.

\section{Conclusions}

Bepridil may be a blocker for the Trek- $1 \mathrm{~K}^{+}$channel at a clinical therapeutic concentration, which provided a new mechanism of Trek-1 channel regulation and bepridil's antiarrhythmic effect. 


\section{Acknowledgments}

A part of data had previously accepted as an abstract in the 29th Great Wall International Congress of Cardiology China Heart Society Beijing Society of Cardiology. We would like to thank AME Editing Service for the help in polishing the language of our paper.

Funding: This study was supported by the National Natural Science Foundation of China (81700891, 81470558, and $81100206)$, the Science and technology research program of Shandong Province (ZR2020MH038 and 2014GSF118143), and the Key Research and Development Project of Shandong Province (2016GSF201184).

\section{Footnote}

Reporting Checklist: The authors have completed the ARRIVE reporting checklist. Available at https://dx.doi. org/10.21037/atm-20-7971

Data Sharing Statement: Available at https://dx.doi. org/10.21037/atm-20-7971

Peer Review File: Available at https://dx.doi.org/10.21037/ atm-20-7971

Conflicts of Interest: All authors have completed the ICMJE uniform disclosure form (available at https://dx.doi. org/10.21037/atm-20-7971). The authors have no conflicts of interest to declare.

Ethical Statement: The authors are accountable for all aspects of the work in ensuring that questions related to the accuracy or integrity of any part of the work are appropriately investigated and resolved. Experiments were performed under a project license (No.: DWLL-2020-042) granted by the Animal Care Committee of Qilu Hospital of Shandong University, in compliance with the Guide for the Care and Use of Laboratory Animals published by the United States National Institutes of Health.

Open Access Statement: This is an Open Access article distributed in accordance with the Creative Commons Attribution-NonCommercial-NoDerivs 4.0 International License (CC BY-NC-ND 4.0), which permits the noncommercial replication and distribution of the article with the strict proviso that no changes or edits are made and the original work is properly cited (including links to both the formal publication through the relevant DOI and the license). See: https://creativecommons.org/licenses/by-nc-nd/4.0/.

\section{References}

1. Kamatham S, Waters CM, Schwingshackl A, Mancarella S. TREK-1 protects the heart against ischemia-reperfusioninduced injury and from adverse remodeling after myocardial infarction. Pflugers Arch 2019;471:1263-72.

2. Patel AJ, Honoré E, Maingret F, et al. A mammalian two pore domain mechano-gated S-like K+ channel. EMBO J 1998;17:4283-90.

3. Niemeyer MI, Cid LP, González W, et al. Gating, Regulation, and Structure in K2P K+ Channels: In Varietate Concordia? Mol Pharmacol 2016;90:309-17.

4. Sepúlveda FV, Pablo Cid L, Teulon J, et al. Molecular aspects of structure, gating, and physiology of $\mathrm{pH}$-sensitive background K2P and Kir K+-transport channels. Physiol Rev 2015;95:179-217.

5. Maingret F, Patel AJ, Lesage F, et al. Mechano- or acid stimulation, two interactive modes of activation of the TREK-1 potassium channel. J Biol Chem 1999;274:26691-6.

6. Nayak TK, Harinath S, Nama S, et al. Inhibition of human two-pore domain $\mathrm{K}+$ channel TREK1 by local anesthetic lidocaine: negative cooperativity and half-ofsites saturation kinetics. Mol Pharmacol 2009;76:903-17.

7. Sandoz G, Douguet D, Chatelain F, et al. Extracellular acidification exerts opposite actions on TREK1 and TREK2 potassium channels via a single conserved histidine residue. Proc Natl Acad Sci U S A 2009;106:14628-33.

8. Decher N, Kiper AK, Rinné S. Stretch-activated potassium currents in the heart: Focus on TREK-1 and arrhythmias. Prog Biophys Mol Biol 2017;130:223-32.

9. Goonetilleke L, Quayle J. TREK-1 K(+) channels in the cardiovascular system: their significance and potential as a therapeutic target. Cardiovasc Ther 2012;30:e23-9.

10. Unudurthi SD, Wu X, Qian L, et al. Two-Pore K+ Channel TREK-1 Regulates Sinoatrial Node Membrane Excitability. J Am Heart Assoc 2016;5:e002865.

11. Lugenbiel P, Wenz F, Syren P, et al. TREK-1 (K(2P)2.1) $\mathrm{K}(+)$ channels are suppressed in patients with atrial fibrillation and heart failure and provide therapeutic targets for rhythm control. Basic Res Cardiol 2017;112:8.

12. Kisselbach J, Seyler C, Schweizer PA, et al. Modulation of K2P 2.1 and K2P $10.1 \mathrm{~K}(+)$ channel sensitivity to carvedilol by alternative mRNA translation initiation. $\mathrm{Br} \mathrm{J}$ Pharmacol 2014;171:5182-94. 
13. Osaka T, Yokoyama E, Kushiyama Y, et al. Opposing effects of bepridil on ventricular repolarization in humans. Inhomogeneous prolongation of the action potential duration vs flattening of its restitution kinetics. Circ J 2009;73:1612-8.

14. Yasuda M, Nakazato Y, Sasaki A, et al. Clinical evaluation of adverse effects during bepridil administration for atrial fibrillation and flutter. Circ J 2006;70:662-6.

15. Wang JC, Kiyosue T, Kiriyama K, et al. Bepridil differentially inhibits two delayed rectifier $\mathrm{K}(+)$ currents, $\mathrm{I}(\mathrm{Kr})$ and $\mathrm{I}(\mathrm{Ks})$, in guinea-pig ventricular myocytes. Br J Pharmacol 1999;128:1733-8.

16. Jin H, Iribe G, Naruse K. Effects of bepridil on stretchactivated BKca channels and stretch-induced extrasystoles in isolated chick hearts. Physiol Res 2017;66:459-65.

17. Li Y, Sato T, Arita M. Bepridil blunts the shortening of action potential duration caused by metabolic inhibition via blockade of ATP-sensitive $\mathrm{K}(+)$ channels and $\mathrm{Na}(+)$-activated $\mathrm{K}(+)$ channels. J Pharmacol Exp Ther 1999;291:562-8.

18. Hollingshead LM, Faulds D, Fitton A. Bepridil. A review of its pharmacological properties and therapeutic use in stable angina pectoris. Drugs 1992;44:835-57.

19. Hwang SJ, O'Kane N, Singer C, et al. Block of inhibitory junction potentials and TREK-1 channels in murine colon by Ca2 + store-active drugs. J Physiol 2008;586:1169-84.

20. Zyrianova T, Lopez B, Olcese R, et al. K2P2.1 (TREK-1) potassium channel activation protects against hyperoxiainduced lung injury. Sci Rep 2020;10:22011.

21. Sauter DR, Sørensen CE, Rapedius M, et al. pH-sensitive $\mathrm{K}(+)$ channel TREK-1 is a novel target in pancreatic cancer. Biochim Biophys Acta 2016;1862:1994-2003.

22. Miller P, Kemp PJ, Lewis A, et al. Acute hypoxia occludes hTREK-1 modulation: re-evaluation of the potential role of tandem $\mathrm{P}$ domain $\mathrm{K}+$ channels in central neuroprotection. J Physiol 2003;548:31-7.

23. Wang YY, Ma ZY, Li XD, et al. Serum positive for the autoantibody against the $\beta(1)$-adrenoceptor from Chinese patients with congestive heart failure decreases $\mathrm{I}(\mathrm{ss})$ in mouse cardiac myocytes. Clin Dev Immunol 2011;2011:143517.

24. Xian Tao Li, Dyachenko V, Zuzarte M, et al. The stretchactivated potassium channel TREK-1 in rat cardiac ventricular muscle. Cardiovasc Res 2006;69:86-97.

25. Papreck JR, Martin EA, Lazzarini P, et al. Modulation of K2P3.1 (TASK-1), K2P9.1 (TASK-3), and TASK$1 / 3$ heteromer by reactive oxygen species. Pflugers Arch 2012;464:471-80.
26. Berman HM, Battistuz T, Bhat TN, et al. The Protein Data Bank. Acta Crystallogr D Biol Crystallogr 2002;58:899-907.

27. Irwin JJ, Shoichet BK. ZINC--a free database of commercially available compounds for virtual screening. J Chem Inf Model 2005;45:177-82.

28. Grosdidier A, Zoete V, Michielin O. SwissDock, a proteinsmall molecule docking web service based on EADock DSS. Nucleic Acids Res 2011;39:W270-7.

29. Pettersen EF, Goddard TD, Huang CC, et al. UCSF Chimera--a visualization system for exploratory research and analysis. J Comput Chem 2004;25:1605-12.

30. Tertyshnikova S, Knox RJ, Plym MJ, et al. BL-1249 [(5,6,7,8-tetrahydro-naphthalen-1-yl)-[2-(1H-tetrazol-5yl)-phenyl]-amine]: a putative potassium channel opener with bladder-relaxant properties. J Pharmacol Exp Ther 2005;313:250-9.

31. Takahara A, Nakamura Y, Sugiyama A. Beat-tobeat variability of repolarization differentiates the extent of torsadogenic potential of multi ion channelblockers bepridil and amiodarone. Eur J Pharmacol 2008;596:127-31.

32. Izumi D, Chinushi M, Iijima K, et al. Effects of bepridil versus E-4031 on transmural ventricular repolarization and inducibility of ventricular tachyarrhythmias in the dog. Pacing Clin Electrophysiol 2010;33:950-9.

33. Prystowsky EN. Effects of bepridil on cardiac electrophysiologic properties. Am J Cardiol 1992;69:63D-7D.

34. Djillani A, Mazella J, Heurteaux C, et al. Role of TREK1 in Health and Disease, Focus on the Central Nervous System. Front Pharmacol 2019;10:379.

35. Vivier D, Bennis K, Lesage F, et al. Perspectives on the Two-Pore Domain Potassium Channel TREK-1 (TWIKRelated K(+) Channel 1). A Novel Therapeutic Target? J Med Chem 2016;59:5149-57.

36. Wang Y, Lv L, Zang H, et al. Regulation of Trek1 expression in nasal mucosa with allergic rhinitis by specific immunotherapy. Cell Biochem Funct 2015;33:23-8.

37. Gardener MJ, Johnson IT, Burnham MP, et al. Functional evidence of a role for two-pore domain potassium channels in rat mesenteric and pulmonary arteries. Br J Pharmacol 2004;142:192-202.

38. Bond RC, Choisy SC, Bryant SM, et al. Inhibition of a TREK-like $\mathrm{K}+$ channel current by noradrenaline requires both $\beta 1$ - and $\beta 2$-adrenoceptors in rat atrial myocytes. Cardiovasc Res 2014;104:206-15.

39. Seyler C, Li J, Schweizer PA, et al. Inhibition of 
cardiac two-pore-domain $\mathrm{K}+(\mathrm{K} 2 \mathrm{P})$ channels by the antiarrhythmic drug vernakalant--comparison with flecainide. Eur J Pharmacol 2014;724:51-7.

40. Wang J, Feng J, Nattel S. Class III antiarrhythmic drug action in experimental atrial fibrillation. Differences in reverse use dependence and effectiveness between d-sotalol and the new antiarrhythmic drug ambasilide. Circulation 1994;90:2032-40.

41. Kamatham S, Waters CM, Schwingshackl A, et al. TREK1 protects the heart against ischemia-reperfusion-induced injury and from adverse remodeling after myocardial infarction. 2019;471:1263-72.

42. Baldoni S, Del Papa B, Dorillo E, et al. Bepridil exhibits anti-leukemic activity associated with NOTCH1 pathway inhibition in chronic lymphocytic leukemia. Int J Cancer 2018;143:958-70.

43. Kato R, Singh BN. Effects of bepridil on the

Cite this article as: Wang Y, Fu Z, Ma Z, Li N, Shang H. Bepridil, a class IV antiarrhythmic agent, can block the TREK1 potassium channel. Ann Transl Med 2021;9(14):1123. doi: 10.21037/atm-20-7971 electrophysiologic properties of isolated canine and rabbit myocardial fibers. Am Heart J 1986;111:271-9.

44. Ma F, Takanari H, Masuda K, et al. Short- and long-term inhibition of cardiac inward-rectifier potassium channel current by an antiarrhythmic drug bepridil. Heart Vessels 2016;31:1176-84.

45. Lolicato M, Arrigoni C, Mori T, et al. K(2P)2.1 (TREK1)-activator complexes reveal a cryptic selectivity filter binding site. Nature 2017;547:364-8.

46. Schmidt C, Wiedmann F, Kallenberger SM, et al. Stretchactivated two-pore-domain (K2P) potassium channels in the heart: Focus on atrial fibrillation and heart failure. Prog Biophys Mol Biol 2017;130:233-43.

47. Decher N, Ortiz-Bonnin B, Friedrich C, et al. Sodium permeable and "hypersensitive" TREK-1 channels cause ventricular tachycardia. EMBO Mol Med 2017;9:403-14. 


\section{Real time fluorescence quantitative RT-PCR}

The whole RNA of U251MG cells was extracted by the Trizol method. Real time fluorescence quantitative RT-PCR was carried out using a protocol from the Applied Biosystems. SYBR Premix Ex TapTMII (including TaKaRa Ex TapTM HS, dNTP compound, $\mathrm{Mg}^{2+}$, SYBR Green I; TaKaRa DRR041) and the primers (GAPDHTGACTTCAACAGCGACACCCA CACCCTGTTGCTGTAGCCAAA; KCNK2, TREK-1, GATTATACCGTTAGGAAACACC TCCCAGTAAGGCATAGATGA) were added in the reaction system. The melting curves and electrophoresis on agarose gel were applied to detect the specificity of the PCR product of every primer reaction. The comparative Trek-1 mRNA expression was calculated by dividing the GAPDH mRNA expression. The threshold cycle (Ct) was determined by the SDS program of ABI Prism. $\Delta$ Ct represented the comparative mRNA expression, $\Delta \mathrm{Ct}=\mathrm{Ct}($ Trek-1 mRNA) $-\mathrm{Ct}(\mathrm{GAPDH})$. Result: Average $\Delta \mathrm{Ct}$ (U251MG) was 15.36 \pm 0.064 , showing the moderate abundance of gene expression in U251MG cells.

\section{Immunofluorescence staining}

Cultured U251MG cell was separated using trypsin and planted onto glass coverslip as used in patch-clamp recordings. Then U251MG cells were fixed with 4\% paraformaldehyde for $1 \mathrm{~h}$. After washing with PBS, Triton X-100 (0.1\%) was used to permeabilize the cells and goat serum (5\%) was used to block nonspecific reactions. The cell was treated by the primary rabbit anti--KCNK2 (TREK-1) antibody (1:100, Alomone Labs) overnight in $4{ }^{\circ} \mathrm{C}$ condition. When washing cells by PBS for three times at $5 \mathrm{~min}$ interval, cells were treated by the fluorescent secondary antibody (FITC-conjugated goat antirabbit IgG, 1:1,000, Sigma) at room temperature. One hour later, the cell nuclei were re-stained by 4',6-diamidino-2phenylindole (DAPI). The fluorescence image was captured using a Zeiss 710 confocal laser scanning microscope (Zeiss, Germany).

Result: TREK-1 was expressed in the cell membrane.

DAPI

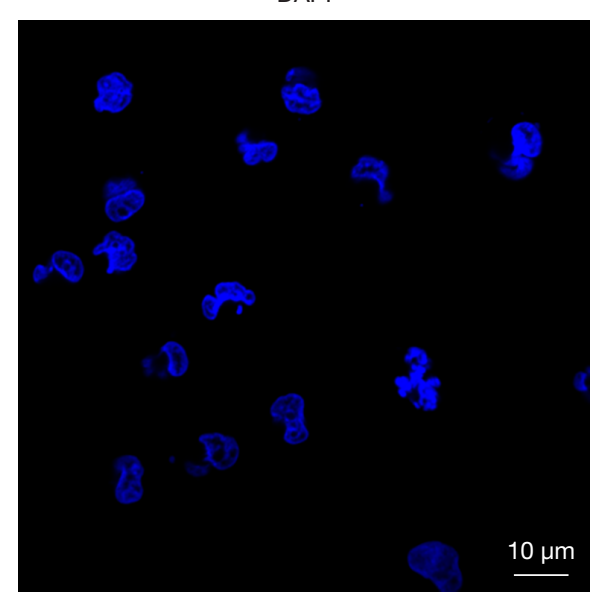

TREK-1

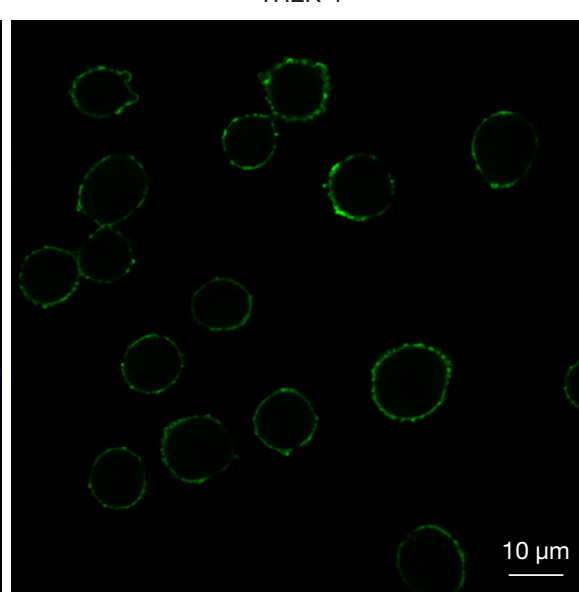

Merged

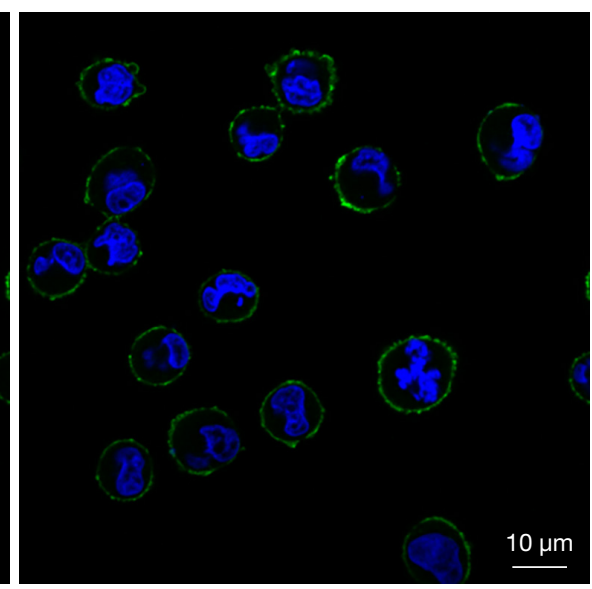

Figure S1 Immunofluorescence staining of TREK-1 in U251MG cells. After being 4\% Paraformaldehyde-fixed and 0.1\% Triton X-100 permeabilized the U251MG cells were labeled with primary rabbit anti-KCNK2 (TREK-1) antibody (1:100, Alomone Labs) followed by the fluorescent secondary antibody (FITC-conjugated goat anti-rabbit IgG, 1:1000, Sigma). The cell nuclei were re-stained by 4',6-diamidino2-phenylindole (DAPI). The fluorescence image was captured using a Zeiss 710 confocal laser scanning microscope (Zeiss, Germany). TREK-1 was expressed in the cell membrane. 